младший научный сотрудник факультета международных отношений Университета Сунь Ятсена

\section{ПЕРСПЕКТИВЫ ИНИЦИАТИВЫ «ОДИН ПОЯС - ОДИН ПУТЬ» В РАЗВИТИИ РОССИЙСКО-КИТАЙСКИХ ЭКОНОМИЧЕСКИХ ОТНОШЕНИЙ}

\section{Аннотация:}

В cmaтье анализируется контекст выдвижения инициативы "Один пояс - один путь». Подчеркиваются мирный характер китайской культуры и характеристики инициативы, которые формируются в этом особенном культурном контексте. Изучаются позитивные перспективы российскокитайского сотрудничества, связанные с рассматриваемой инициативой.

\section{Ключевые слова:}

инициатива "Один пояс - один путь», российскокитайские отношения, сотрудничество, мораль, традиционная китайская философия.
Associate Research Fellow, School of International Relations, Sun Yat-sen University

\section{PROSPECTS OF ONE BELT ONE ROAD INITIATIVE IN THE DEVELOPMENT OF RUSSIA-CHINA ECONOMIC RELATIONS}

This article analyzes the background of One Belt One Road Initiative. The research emphasizes the peaceful character of Chinese culture and the attributes of One Belt One Road Initiative, which have formed in the special cultural background. The paper studies the positive prospects of Russia-China cooperation brought by OBOR initiative.

Keywords: One Belt One Road Initiative, Russia-China relations, cooperation, morality, traditional Chinese philosophy.

«Один пояс - один путь» (ОПОП) - так обычно называют объединенный проект создания «Экономического пояса Шелкового пути» и «Морского Шелкового пути XXI в.», выдвинутый по инициативе Председателя Китайской Народной Республики Си Цзиньпина во время его визита в Египет. Эта инициатива привлекла внимание международного сообщества и продолжает вызывать полемику. Некоторые относятся к проекту ОПОП позитивно, считая его полезным и выгодным для всех стран, которые в нем участвуют. Например, ведущий эксперт Института мировой экономики и политики при Фонде Первого Президента Республики Казахстан А.А. Нурсеитов подчеркивает: «Расширение взаимовыгодного торгово-экономического и инвестиционного сотрудничества стран, расположенных вдоль древнего Шелкового пути, приведет к превращению Центральной Евразии в регион стратегической стабильности, политической безопасности и экономического прогресса» [1]. Другие сомневаются в намерениях Китая, пытаясь убедить оппонентов в том, что наибольший выигрыш от этого проекта получит сам Китай [2]. С учетом различных мнений проанализируем, почему именно Китай выступил с этой инициативой, чего он стремится достичь и какое влияние проект ОПОП будет оказывать на российско-китайские отношения?

В последнее время соотношение сил между великими державами подвержено серьезным изменениям, которые принесли Китаю как новые вызовы, так и новые возможности. С одной стороны, из-за ряда фракторов, таких как экономический кризис, война в Ираке и Афрганистане, снижается роль Америки как сверхдержавы. Миграционный кризис, выход Великобритании из Европейского союза (EC), повышение популярности партии правого крыла «Национальный фрронт» во Франции подорвали доверие к интеграции и вызвали полемику о будущем ЕС. Все эти фракторы заставляют западные страны сосредоточиться на своих делах и дают Китаю время и пространство для своего развития. После окончания холодной войны в Азии не было вооруженных конфрликтов, не существовало прямой военной угрозы Китаю со стороны соседних стран. В связи с этим с точки зрения безопасности обстановка в Китае существенно улучшилась. Но вместе с тем Китай должен отвечать на ряд вызовов на разных уровнях.

На международном уровне - с 2010 г. США вынуждены сосредоточить свою стратегию на Азиатско-Тихоокеанском регионе, руководствуясь политикой «опорного пункта» в Азии. Вашингтон намерен сдержать возрастающее влияние Китая в Азии, так как Китай считается возможной долгосрочной угрозой интересам США в мире. Таким образом, США активно вмешиваются в морскую политику в акватории Южно-Китайского моря, усиливают сотрудничество с Японией и Филиппинами в области безопасности и отправляют вооруженные силы в Австралию. Целью этих операций является создание союза, противостоящего Китаю.

На региональном уровне - из-за отсутствия совместных действий и взаимного доверия экономическая и геополитическая интеграция Китая с соседними странами не стала благоприятным фактором, стимулирующим развитие этих стран. Наоборот, такие проблемы, как терроризм, 
отсталость технологий и оборудования, отсутствие ресурсов, иррациональные экономические формы, препятствовали данному процессу. Известно, что ресурсы играют важную роль в развитии любой страны. Как страна с большим населением и недостаточными ресурсами, Китай стремится найти новые источники для внутреннего развития. Россия и среднеазиатские страны, которые обладают большим запасом ресурсов и находятся рядом с Китаем, являются для него идеальными партнерами.

На государственном уровне - Китай столкнулся с экономическим застоем. В течение 30 лет Китай активно развивался экономически, благодаря чему превратился из бедной, закрытой, сельскохозяйственной страны в один из крупнейших торговых центров в мире. Инвестиции Китая в производство и экспорт в развивающиеся страны определяют статус Китая как второй экономики в мире после США. Но с 2007 г. экономическое развитие Китая замедлилось. По данным Китайского государственного бюро статистики, ВВП Китая в 2007 г. составлял 27 023,227 млрд юаней (рост 14,2 \%), в 2011 г. - 48 930,097 млрд юаней (рост - 9,49 \%). В 2014 г. рост ВВП составил 7,27 \% [3].

Именно в таком контексте была выдвинута инициатива ОПОП. Китайское правительство стремится привлечь к сотрудничеству с Китаем большее количество стран, создавая условия открытости и равных возможностей. Таким образом, Китай может не только стимулировать свое экономическое развитие, но изменить старый международный порядок и даже создать новый. Реалисты и неореалисты используют понятие «баланс» как определяющее для стратегии страны и разделяют эту стратегию на «баланс сил» [4, р. 187], «баланс интересов» [5, р. 166] и «баланс угроз» [6, р. 22]. По этой теории Китай стремится защитить свои интересы в сфере безопасности с помощью баланса угроз и сил.

Китай является страной, обладающей особой культурой. Для китайской культуры определяющим представляется моральный уровень человека, в ней есть понятие «высокоморальный человек». Государство, в котором был создан гипертрофированный образ морального человека, должно культивировать такие положительные ценности, как скромность, честность, доброжелательность и праведность. Таким образом, во внешней политике китайское правительство выдвинуло ряд особых понятий. Например, «ответственная держава», «мирный подъем» и т. д. Подобно высокоморальному человеку, Китай как государство принесет миру новый опыт, которого не было в европейской истории.

Итак, инициатива ОПОП имеет следующие характеристики.

Во-первых, ОПОП стремится создать открытую, свободную и широкую платформу для сотрудничества. В научном сообществе неореалисты признают огромное значение международного сотрудничества для разных стран в эпоху глобализации. Но они считают, что сотрудничество редко бывает успешным, потому что в анархическом международном сообществе международная деятельность осуществляется под руководством сильных государств [7]. Иными словами, страны соглашаются на сотрудничество не по своему собственному желанию, а по желанию стран, которые являются гегемониями. Международное сотрудничество осуществляется при определенном соотношении сил. Когда оно меняется, сотрудничество заканчивается. Для более долгосрочного и стабильного сотрудничества программа ОПОП предполагает обеспечение большей свободы и открытости. Страны с разной историей, идеологией и политической ориентацией могут стать участниками этого проекта и получить равный доступ к выгодам. Когда договор и проект закончатся, участвующие страны могут снова присоединиться к проекту или выйти из него. Таким образом, китайское правительство стремится организовать сотрудничество на основе общих интересов, чтобы уменьшить влияние, связанное с изменениями международной структуры.

Во-вторых, ОПОП стремится создать механизм сотрудничества, который максимально уменьшает риск конфликтов. Неолибералы считают, что сотрудничество может уменьшать риск войн и конфрликтов, так как оно повышает стоимость вооруженных действий. Неореалисты выражают сомнение и пытаются убедить в том, что непропорциональное распределение прибыли от торговли и неравные возможности в мире, где сильна взаимозависимость, приводят к политическим конфликтам между экономическими партнерами, так как сильное государство часто манипулирует условиями экономического обмена [8]. В инициативе ОПОП не существует отношения «руководитель - подчиненный». В китайской культуре слово «гегемония» имеет отрицательную коннотацию. Высокоморальный человек должен заслужить уважение и повиновение благодаря своим справедливым действиям. Поэтому Китай не стремится создать гегемонию или сферу влияния, не вмешивается в распределение прибыли от торговли. Китай относится ко всем странам как к партнерам, которые имеют равные статус и доступ к сотрудничеству, что уменьшает риск конфрликтов.

В-третьих, инициатива ОПОП выдвинута на основе традиционной китайской философрии. С одной стороны, она уделяет внимание практическим проблемам и избегает традиционных лозунгов. С другой стороны, она основана на убеждении, что национальные интересы хоть и важны для всех стран, но средства достижения целей должны соответствовать принципам морали. Иными словами, государство должно заботиться не только о выгоде, но и о морали. Таким образом, 
сотрудничество в рамках ОПОП носит практический характер, например научный обмен, сотрудничество СМИ, волонтерское движение, которые обычно называют «народной дипломатией» (people-to-people bond). Кроме того, эта инициатива как носитель китайских политических ценностей поддерживает ценность и китайскую внешнюю политику «мирного подъема».

ОПОП оказалась столь популярной, что уже более 100 государств и международных организаций присоединились к инициативе. Китай подписал соглашение о сотрудничестве с более чем 30 странами, которые расположены по намеченному маршруту. Также Китай взаимодействует с более чем 20 странами в области производительных мощностей. Азиатский банк инфрраструктурных инвестиций (АБИИ) и Фонд Шелкового пути, созданные на основе инициативы ОПОП, демонстрируют новые фрормы финансового сотрудничества между экономическими партнерами [9].

С развитием инициативы ОПОП вопрос определения роли Китая по отношению к России в будущем стал одним из наиболее значимых и активно исследуемых российскими академическими учреждениями. Всероссийский центр изучения общественного мнения (ВЦИОМ) в 2014 г. проводил опрос российских граждан о состоянии российско-китайских отношений. На вопрос: «Как Вам кажется, кем сегодня является Китай для России?» - 49 \% респондентов ответили «стратегическим и экономическим партнером», 36 \% - «дружественным государством, союзником», 8 \% выразили негативное мнение о роли Китая и определили его как «экономического и политического соперника, конкурента», 1 \% назвал Китай «враждебным государством, вероятным противником». 6 \% опрошенных затруднились с ответом. На вопрос: «Как Вы думаете, в XXI в. Китай будет другом или врагом для России?» - 43 \% респондентов определили роль Китая как «союзника, дружественного государства», 36 \% - «близкого партнера», 9 \% - «опасного соседа, соперника», 1 \% - «противника, врага». 11 \% опрошенных затруднились с ответом [10].

Результаты исследования показывают в целом положительное мнение россиян о Китае, однако количество респондентов, которые позитивно относятся к роли Китая в отношении будущего России, меньше, чем респондентов, которые позитивно оценивают роль Китая для России в настоящее время.

В 2016 г. нами был проведен опрос в Санкт-Петербургском государственном университете, Балтийском государственном техническом университете «Военмех» им. Д.Ф. Устинова и Московском государственном институте международных отношений среди 300 исследователей по международным отношениям. Результаты авторского исследования подтверждают описанную выше тенденцию. Распределение ответов, полученных на вопрос о роли современного Китая (всего 234), выглядит следующим образом: «союзник» - 37, «партнер» - 182, «соперник» - 9, «враг или возможный враг» - 6. Относительно роли будущего Китая мнение этих опрошенных менее позитивно: «союзник» - 50, «партнер» - 148, «соперник» - 33, «враг или возможный враг» - 3. Отметим, что относительно роли Китая в будущем вариант ответа «союзник» избирается чаще на $5,56 \%$, «соперник» - на 10,3 \%, «партнер» - реже на 14,53 \% (табл. 1).

Таблица 1 - Распределение ответов респондентов о роли Китая для России в настоящее время и в будущем, человек (\%)

\begin{tabular}{|l|c|c|}
\hline & $\begin{array}{c}\text { Роль Китая для России } \\
\text { в настоящее время }\end{array}$ & $\begin{array}{c}\text { Роль Китая для России } \\
\text { в будущем }\end{array}$ \\
\hline Союзник & $37(15,81)$ & $50(21,37)$ \\
\hline Партнер & $182(77,78)$ & $148(63,25)$ \\
\hline Соперник & $9(3,85)$ & $33(14,1)$ \\
\hline Враг или возможный враг & $6(2,56)$ & $3(1,28)$ \\
\hline
\end{tabular}

Отсутствие согласия и налаженного механизма сотрудничества в международном сообществе вынуждает государства полагаться на собственные силы в вопросах обеспечения своей безопасности. Благодаря экономическому развитию, Китай стремится наращивать военную мощь. При этом стоит отметить, что китайская философия отличается от европейской тем, что подчеркивает моральные ценности человека, политических лидеров и государства. Развитие Китая отличается от подъема европейских стран мирным характером. Таким образом, по нашему мнению, для России Китай будет мирным партнером, а не агрессивным соперником.

Помимо этого, развивающиеся отношения между Китаем и Россией в различных областях создают взаимозависимость, которая уменьшает возможность вооруженных конфликтов, так как они экономически нецелесообразны. С точки зрения автора, огромное значение инициативы ОПОП для России заключается в том, что она может улучшить политическую обстановку вокруг России. Во время холодной войны США относились к СССР как к сопернику, опаснейшему врагу и сдерживали развитие СССР в различных областях. После распада СССР западные страны не отрицают возможность новой холодной войны. Намерение России вернуть себе статус мировой 
военной державы является вызовом Америке как единственной сверхдержаве, стремящейся сохранить свою гегемонию. Таким образом, в условиях старого международного порядка, власть в котором принадлежит США, Россия сталкивается с рисками и проблемами, угрожающими ее безопасности. Западные страны стремятся ослабить Россию, даже раздробить ее. Из-за этого экономика России существенно пострадала в последние годы. Во-первых, цены на нефть снизились на 50 \% от максимального значения в июне 2014 г. до минимального, зафиксированного 16 декабря 2014 г. [11]. Во-вторых, после начала украинского кризиса администрация Обамы ввела ряд санкций против России, из-за чего рубль обесценился более чем на 50 \% по сравнению с июлем 2014 г. [12].

Инициатива ОПОП предлагает России возможный выход из сложившейся ситуации. С помощью сотрудничества Россия может стимулировать экономическое развитие, повышать свою мощь, оказывать влияние на распределение сил в мире. В сравнении с политическими конфрликтами, которые обходятся слишком дорого, изменение распределения сил, не требующее больших затрат, может повлиять на существующую и помочь создать новую, более благоприятную структуру международного взаимодействия. Таким образом, инициатива ОПОП может оказаться для России не столько вызовом, сколько источником новых возможностей. И Китай, и Россия могут успешно развиваться дальше.

\section{Ссылки и примечания:}

1. Нурсеитов А.А. Экономический пояс Шелкового пути: возможности и перспективы [Электронный pecypc]. URL: http://yvision.kz/post/520219 (дата обращения: 07.05.2017).

2. Li Yi. Explainer: China's One Belt One Road Initiative [Электронный pecypc]. URL: https://www.hongkongfp.com/2016/03/06/explainer-chinas-one-belt-one-road-initiative/ (дата обращения: 07.05.2017).

3. National Bureau of Statistics of China [Электронный ресурc]. URL: http://data.stats.gov.cn/ks.htm?cn=C01\&zb=A0501 (дата обращения: 07.05.2017).

4. Morgenthau H.J. Politics among nations: the struggle for power and peace. 7th ed. Boston, 2006. $752 \mathrm{p}$

5. Waltz K.N. Theory of international politics. Long Grove, 2010. 251 p.

6. Walt S.M. The origins of alliances. Ithaca, $1987.336 \mathrm{p}$.

7. Такое мнение отражено в следующих работах: Gilpin R. War and change in the world politics. Cambridge, UK, 2002. 288 p. ; Grieco J.M. Cooperation among nations: Europe, America and non-tariff barriers to trade. Ithaca, 1990. 260 p. ; Waltz K.N. Theory of international politics. Long Grove, 2010. 251 p.

8. Waltz K.N. Globalization and governance // PS: Political Science and Politics. 1999. Vol. 32, no. 4. P. 693-700. https://doi.org/10.2307/420158

9. Ян Сунбо. Речь Си Цзиньпина [Электронный ресурс]. На кит. яз. URL: http://news.ifeng.com/a/20160820/49811794 0.shtml (дата обращения: 07.05.2017).

10. Россия - Китай: от вражды и конкуренции - к дружбе и сотрудничеству [Электронный ресурс] : пресс-выпуск № 2708. 2014. 6 нояб. URL: http://wciom.ru/index.php?id=236\&uid=115042 (дата обращения: 07.05.2017).

11. Bowler T. Falling oil prices: who are the winners and losers? [Электронный pecypc]. URL: http://www.bbc.com/news/business-29643612 (дата обращения: 07.05.2017).

12. По данным Центрального банка Российской Федерации (http://cbr.ru/currency_base/daily.aspx).

\section{References}

Bowler, T 2017, Falling oil prices: who are the winners and losers?, viewed 07 May 2017, <http://www.bbc.com/news/business-29643612>.

Gilpin, R 2002, War and change in the world politics, Cambridge, UK, 288 p.

Grieco, JM 1990, Cooperation among nations: Europe, America and non-tariff barriers to trade, Ithaca, $260 \mathrm{p}$.

$\mathrm{Li} \mathrm{Yi}$, 2017, Explainer: China's One Belt One Road Initiative, viewed 07 May 2017, <https://www.hongkongfp.com/2016/03/06/explainer-chinas-one-belt-one-road-initiative/>.

Morgenthau, HJ 2006, Politics among nations: the struggle for power and peace, 7th ed., Boston, $752 \mathrm{p}$

National Bureau of Statistics of China 2017, viewed 07 May 2017, <http://data.stats.gov.cn/ks.htm?cn=C01\&zb=A0501>

Nurseitov, AA 2017, The economic belt of the Silk Road: opportunities and prospects, viewed 07 May 2017, <http://yvision.kz/post/520219>, (in Russian).

Russia-China: from enmity and competition to friendship and cooperation 2014, Press Release No. 2708, 6 November, viewed 07 May 2017, <http://wciom.ru/index.php?id=236\&uid=115042>, (in Russian).

Songbo, Ya 2017, Xi Jinping's speech, viewed 07 May 2017, <http://news.ifeng.com/a/20160820/49811794_0.shtml>, (in Chinese).

Walt, SM 1987, The origins of alliances, Ithaca, $336 \mathrm{p}$.

Waltz, KN 1999, 'Globalization and governance', PS: Political Science and Politics, vol. 32, no. 4, pp. 693-700. https://doi.org/10.2307/420158

Waltz, KN 2010, Theory of international politics, Long Grove, 251 p. 